\title{
PROCEDIMENTO PARA IDENTIFICAÇÃO, RECONHECIMENTO, DELIMITAÇÃO, DEMARCAÇÃO E TITULAÇÃO DAS TERRAS QUILOMBOLAS
}

\author{
A PROCEDURE TO IDENTIFY, RECOGNIZE, DELIMIT, DEMARCATE AND \\ TITRATION OF QUILOMBOLA'S SPACE
}

\author{
Ana Clara Correa Henning * \\ Robson Jardel Santos Leal ${ }^{* *}$ \\ Thais Luzia Colaço ${ }^{* * *}$
}

Data de recebimento: $23 / 02 / 2015$

Data da aprovação: 10/06/2015

\section{RESUMO}

O presente trabalho aborda a normatização jurídica de regularização fundiária de áreas ocupadas por remanescentes de comunidades de quilombos. Realizamos pesquisa bibliográfica, legislativa e de dados empíricos disponibilizados por órgãos responsáveis pela efetivação desse procedimento. O resultado foi, textualmente, um breve relato histórico de questões relativas à escravidão negra no Brasil, apontando a atualidade de suas marcas; em seguida, ressaltou-se a conexão entre a propriedade quilombola e os dispositivos constitucionais. Por fim, discorreu-se sobre as diversas

\footnotetext{
* Graduada em Direito (UFPel), Epecialista em Direito (UNISINOS), Mestre em Educação (UFPel), Mestre em Direito (PUCRS) e Doutoranda em Direito (UFSC). Membro do Grupo de Pesquisa em Antropologia Jurídica (GPAJU) da UFSC. Membro do Grupo de Pesquisa Imagens da Justiça, da UFPel. Bolsista CAPES.

E-mail: anaclaracorreahenning@gmail.com

** Possui graduação em Direito pela Faculdade Atlântico Sul de Pelotas (2012). Tem experiência na área de Direito. E-mail: sgtjardel@hotmail.com

*** Pós-doutora em Direito (Universidade de Sevilha), Doutora em Direito (Universidade de Santa Catarina). Professora titular de Antropologia Jurídica no Curso de Direito da UFSC. Professora no Programa de Pós-Graduação em Direito da UFSC. Coordenadora do Grupo de Pesquisa em Antropologia Jurídica da UFSC. E-mail: thaisluziacolaco@gmail.com
} 
regras jurídicas e os órgãos responsáveis pela identificação, reconhecimento, delimitação, demarcação e titulação dessas propriedades, apresentando um fluxograma com o objetivo de sintetizar e organizar didaticamente a teia de normatizações que estabelece esses procedimentos.

\title{
PALAVRAS-CHAVE
}

Quilombos, Regularização da Propriedade, Legislação Nacional.

\begin{abstract}
This essay talks about the juridical normalization of areas occupied by Quilombola's communities remaining and their land regularization. It was made a bibliographic research, a legislative research, as well as, empirical research based on documents available in organizations responsible for the effectiveness of this process. The result was, textually, a brief historical report of questions focus on the black people slavery in Brazil, pointing what is seen nowadays; after that, it was stressed the connection between the quilombola's property and the constitutional dispositive. Finally, it was discoursed about the many juridical rules and the organizations responsible for the identification, recognition, delimitation, demarcation and titillation of this properties, presenting a flowchart which the main reason was to synthesize and organize didactically the norms that establish this procedures.
\end{abstract}

\section{KEY-WORDS}

Quilombos; Property regularization; National legislation. 


\section{INTRODUÇÃO}

A questão da regulamentação de terras quilombolas no Brasil é, mesmo após o seu reconhecimento pela Constituição Federal de 1988, palco de debates, avanços e retrocessos. A legislação que regula a matéria é intrincada e sobreposta. Daí a necessidade de sua sistematização.

Antes disso, porém, faremos referências, ainda que breves, ao tratamento da etnia negra no Brasil escravocrata, necessárias a fim de compreender o resgate histórico e o equilíbrio social que se procura efetivar hoje, não somente no texto constitucional, como também em legislações infraconstitucionais pertinentes ao tema.

Em seguida, conectaremos tais regramentos a dispositivos constitucionais como a igualdade, a função social da propriedade e os direitos culturais. Enfim, indicaremos os trâmites procedimentais necessários à final titulação dessa propriedade, procurando organizar de maneira didática e, através de um fluxograma, as etapas necessárias à concretização do domínio de terras de remanescentes de quilombos brasileiros para, ao final, tecer algumas críticas acerca deste procedimento.

\section{QUILOMBOS: BREVE RELATO HISTÓRICO E NORMATIZAÇÕES JURÍDICAS CONTEMPORÂNEAS NO BRASIL}

A escravidão negra teve longa duração em diversas partes do mundo. Durante aproximadamente 400 anos, entre os séculos XVI e XIX, o empreendimento escravocrata ocupou um lugar de destaque na economia mundial (GOMES, 2008). Com altas taxas de mortalidade, a travessia marítima da África às Américas e à Europa impunha aos capturados uma dura disciplina em porões imundos e apertados, alimentação parca e exposição a diversas doenças. Castro Alves (2015) sintetizou muito bem tais viagens:

Ontem a Serra Leoa,

A guerra, a caça ao leão,

O sono dormido à toa

Sob as tendas d'amplidão!

Hoje... o porão negro, fundo,

Infecto, apertado, imundo,

Tendo a peste por jaguar...

E o sono sempre cortado

Pelo arranco de um finado,

E o baque de um corpo ao mar. 
Atualmente, sabe-se que "mais de três milhões de cativos africanos foram para as plantações de açúcar e café e para as minas do Brasil" e que temos "uma população de afro-descendentes de mais de 50 milhões, a segunda maior população de ascendência africana no mundo depois da Nigéria" (COTTROL, 2004, p. 118). ${ }^{1}$

A chegada em terras brasileiras conduzia os escravos à venda em mercados. O preço estabelecido, o contrato firmado, as obrigações daí advindas - tudo era regulado pelo direito, que proporcionou o suporte jurídico para tais transações:

Sua validade jurídica era garantida pelo direito, instrumento de manutenção da forma de produção que sustentava a economia. O escravo era, juridicamente, um ser sem alma, apenas uma mercadoria adquirida a um preço estabelecido entre comprador e vendedor (HENNING et al, 2010, s/p).

Essas mercadorias eram comercializadas conforme a idade, o sexo e a procedência. Diante dessas características, era estipulado o seu valor, variando este entre 30 e 40 libras esterlinas, chegando, em certos momentos, a valer quase 100 libras (LAGO, 2014). Havia grande procura e interesse pela mão de obra escrava tanto nas cidades quanto no campo - trabalhadores ora destinados a tarefas perigosas, ora ao cuidado de famílias: em ambos os casos, a uma vida de exaustão e servidão. Isso também porque:

[...] escravos não eram considerados juridicamente humanos na sociedade brasileira, eram semoventes, sujeitos a regimes de engorda e reprodução. Pior do que ser uma pessoa desprovida de 'liberdade individual' é ser uma 'coisa', na maioria das vezes, destituída de valor de humanidade e da condição de pessoa. Embora autores destaquem o vínculo que se estabelecia entre senhores e escravos, acredito que essa dimensão do afeto era rarefeita e com uma pequena parte da escravaria, notadamente os escravos da casa-grande (MÜLLER, 2011, p. 34).

As rebeliões e fugas não tardaram. Muitos eram pegos e levados de volta, surrados e castigados, às vezes até a morte. Há relatos históricos de extermínio em massa por forças armadas estatais em combinação com milícias privadas ou locais, tal como o que segue:

\footnotetext{
${ }^{1}$ Do original: "More than three million African captives went to the sugar and coffee plantations and mines of Brazil [...] Brazil has an Africa-descendent population of over fifty million, the second-largest population of African descent in the world after Nigeria". Tradução livre dos autores.
} 
[...] Crianças berraram. As mães taparam-lhe a boca com as mãos. Quem pôde pegou em armas. Os homens saíram ao ataque. Vieram mais negros, passaram pelos policiais entre as ramagens e coquiaram-lhes a cabeça com pauladas. Caiu um, caíram dois, três... Na parede de uma choupana escorregou um preto baleado. Outro que corria na direção do poço tombou no meio do caminho. Uma mulher ficou atocaiada dentro da choupana. Dois soldados vieram um pela janela e outro pela porta e tacaram bala, ao mesmo tempo, no corpo da negra que rolou no chão sem gritar. A correria era grande (DE LEÓN, 1991, p. 75).

Entretanto, muitos conseguiam evadir-se dos capitães do mato e permanecer escondidos em lugares ermos, formando grupos com outros fugitivos. Ali, nos quilombos, entre cabanas rústicas, em meio à mata e caminhos camuflados, os "asilados naqueles matos e naquelas serras, deixavam de ser uma coisa falante para recobrar a sua dignidade humana" (FREITAS, 1991, p. 36). Constituíam comunidades isoladas, formadas em locais distantes do perímetro urbano. Igualmente seus territórios advinham de conquista de terras por doações, heranças, serviços prestados ao Estado, permanência nas terras que ocupavam e cultivavam no interior de grandes propriedades, bem como a compra de terras, tanto durante a escravatura quanto após a abolição (RUBERT, 2008, p. 168-169).

Com o passar do tempo, em ordem cronológica foram publicadas várias leis, que, pouco a pouco, reconheciam a liberdade a diversos grupos de escravos, até que em 1888 foi declarado o fim da escravidão no Brasil. Não obstante, o longo período escravocrata nos legou inúmeras marcas sociais:

Ainda hoje ressoam na sociedade brasileira os ecos da perversidade escravocrata, por meio, por exemplo do preconceito de cor que sofrem os brasileiros de pele escura. É comum se ouvir que tal preconceito - acaso existente - não é baseado na cor, mas sim na classe social, sem que se explicite, como demonstram as estatísticas, que são negros e pardos aqueles que compõem a maioria das classes menos privilegiadas (BRILHANTE, 2009, p. 3.370).

As estatísticas impressionam: em dados disponibilizados pelo Instituto de Pesquisa Econômica Aplicada (IPEA, 2012), os negros permanecem menor tempo nas instituições de ensino (5,7 anos em contraposição a 7,4 anos para os brancos); possuem maior taxa de analfabetismo (12,8 pontos em comparação com os 5,7 para brancos) e auferem menos que a metade da renda que chefes de família 
brancos (média de $\mathrm{R} \$ 416,09$ mensais contra $\mathrm{R} \$ 854,07$ ). Isso nos diz que a questão da propriedade quilombola é muito maior do que um mero resgate histórico - ela é uma discussão que também leva em conta a grande disparidade entre etnias no Brasil contemporâneo.

Aqueles quilombos, outrora em locais isolados e habitados por escravos negros fugitivos e libertos, hoje se perpetuam em territórios ocupados por seus descendentes. Mesmo com o término da escravidão, muitas pessoas (negras ou não) continuaram vivendo nas comunidades quilombolas, preservando os costumes e a cultura de seus antepassados.

Assim, pensar a identidade quilombola é refletir sobre a territorialidade complexa, multifacetada e diversa do país. Continuam vivas nestes lugares tradições religiosas e festivas de candomblé, umbanda, tambor de mina, tambor de crioula, bumba-meu-boi, reisado, festa do divino, festa de caboclo, ladainhas para santos e encantados. Não são artigos folclóricos estáticos, fechados em si e pendurados no tempo: são manifestações vivas e plenas de vontade própria, que continuam mantendo - por vezes descobrindo - seu sentido para as pessoas que as praticam, que continuam em processo de transmutação em contato com o mundo, ao qual ainda fazem referência e tomando parte daquilo que somos e desejamos ser (ANJOS, CIPRIANO, 2006, p. 75).

A Convenção n. 169 da Organização Internacional do Trabalho (OIT, 2002) foi o primeiro documento internacional vinculante que reconheceu direitos às terras ocupadas por povos originários ou tribais, cuja organização social os diferencia da maioria da população. A Constituição Federal de 1988 (CF/88), por sua vez, reconheceu a propriedade quilombola em seu art. 68 do Ato das Disposições Constitucionais Transitórias (ADCT): “Aos remanescentes das comunidades dos quilombos que estejam ocupando suas terras é reconhecida a propriedade definitiva, devendo o Estado emitir-lhes os títulos respectivos" (BRASIL, 1988). Sua regulamentação se dá pelo Decreto n. 4.887, de 20 de novembro de 2003, que caracteriza quilombos da seguinte forma:

Consideram-se remanescentes das comunidades dos quilombos, para os fins deste Decreto, os grupos étnicos raciais, segundo critérios de autoatribuição, com trajetória histórica própria, dotados de relações territoriais específicas, com presunção de ancestralidade negra relacionada com a resistência à opressão histórica sofrida (BRASIL, 2003). 
Comunidades quilombolas situam-se de norte a sul do país, não só no meio rural, mas também no urbano. E a sua utilização e domínio trazem modificações ao antigo direito de propriedade, considerado eminentemente de direito privado, absoluto e individual (NASCIMENTO, 2003): sobre seus regramentos, incidem princípios constitucionais como a igualdade e a função social da propriedade, além dos denominados direitos culturais. Falar em propriedade privada hoje é falar em um instituto permeado de dimensões públicas (PERLINGIERI, 2008).

No que diz com o princípio da igualdade, é mandamento constitucional que todos temos direito a iguais oportunidades de vida e, caso constatada a desigualdade material de certos grupos, o direito tem a tarefa de equilibrar a sociedade. $\mathrm{Na}$ percepção de Jorge Miranda:

Está em causa, antes de mais, o reconhecimento aos cidadãos pertencentes a uma minoria dos mesmos direitos e das mesmas condições de exercício dos direitos dos demais cidadãos. Mas não basta evitar ou superar a discriminação. É necessário assegurar o respeito da identidade do grupo e propiciar-lhe meios de preservação e de livre desenvolvimento. Donde a atribuição de direitos particulares - de direitos fundamentais próprios desses grupos, de carácter individual ou institucional - e a prescrição ao Estado de correspondentes incumbências (grifos nossos) (MIRANDA, 2002, p. 195).

Ingo Sarlet (2010) já afirmou a existência de direitos fundamentais fora do catálogo do art. $5^{\circ}$ a 17 da CF/88 (BRASIL, 1988). Assim a literatura especializada (MALMANN, 2011) vem entendendo a previsão no art. 68 do ADCT - um direito fundamental de um grupo cuja realidade concreta é de exclusão e, por vezes, invisibilidade. Além dessa igualdade material, a $\mathrm{CF} / 88$ prevê o disposto no art. $5^{\circ}$, inc. XXIII:"a propriedade atenderá a sua função social”, prescrição também constante no seu art. 170, inc. II e III (BRASIL, 1988).Da mesma forma, o Código Civil de 2002, no art. 1.228, $\S 1^{\circ}$ (BRASIL, 2002). Segundo Luciano de Camargo Penteado:

A propriedade surge como tema constitucional para a proteção de um círculo existencial. Visa a estruturação de um espaço sobre o que a pessoa possa configurar e receber a configuração da própria personalidade. Este, entretanto, perdeu o sentido de mera proteção da identidade da pessoa para assumir um papel ético de permitir, em via reversa, a formação da personalidade, a partir de um espaço vital configurado por bens. A busca pela extensão e generalização deste valor a todos os indivíduos, faz 
da própria função social da propriedade um standard. Seu sentido é permitir a atribuição da propriedade para os que não tem bens, ao mesmo tempo em que é mecanismo de proteção a bens difusos [...] (itálicos no original, grifos nossos) (PENTEADO, 2008, p. 189-190).

Nesse contexto, a propriedade está ligada à ordem econômica e deve, necessariamente, proporcionar justiça social, que é condição prévia para o exercício da dignidade da pessoa humana (CF/88, art. $1^{\circ}$, inc. III) (BRASIL, 1988). Em nosso ordenamento jurídico, inúmeras leis impõem restrições ao direito de propriedade, como o Código de Mineração, o Código Florestal, a Lei de Proteção do Meio Ambiente, etc. Note-se, entretanto, que a função social não é entendida como mais uma dessas restrições, mas faz parte do próprio conceito da propriedade contemporânea - não existe situação proprietária sem a sua funcionalização (PERLINGIERI, 2008). Entende-se, assim, que ela "não pode bastar à satisfação do seu titular; é preciso, outrossim, que se adéque à preservação do meio ambiente natural e social, com escopo coletivo e difuso" (NOGUEIRA, 2013, p. 70).

Ao conectar essa função social com a propriedade quilombola, duas questões devem ser indicadas - ambas de fundo histórico e social. De início, atentamos para a Lei da Terra de 1850, cujo texto impossibilitava, ainda que indiretamente, às pessoas negras tornarem-se proprietárias de terras, estabelecendo o requisito da compra de particulares ou do governo (BRASIL, 1850). Sendo escravas, trabalhando forçadamente de maneira gratuita, logicamente não possuíam o valor suficiente para adquirirem terras de alguém e tornarem-se proprietárias. Isso nos leva à observação de que grande parte dos negros que naquele período estabeleciam-se em um terreno exerciam posse e não propriedade.

A segunda questão está ligada a essa utilização histórica da terra. Nela, os escravos e libertos cultivavam formas de vida ligadas à ancestralidade africana $\mathrm{e}$ socialidades que não poderiam estabelecer fora dos quilombos. A partir daí, a contemporânea funcionalização das terras de quilombos é auferida pelo seu valor cultural e não pela mera produtividade. Ela é remanescência histórica, resignificado da memória, sendo substrato da própria identidade do grupo (CIRNE, 2010).

Quanto aos direitos culturais, o artigo $215^{\circ} \S 1^{\circ} \mathrm{CF} / 88$ (BRASIL, 1988) prevê que é dever do Estado zelar pela proteção das manifestações das culturas afrobrasileiras. Logo adiante, o artigo $216^{\circ} \S 5^{\circ}$ estabelece o tombamento de todos os sítios onde há lembranças históricas dos antigos quilombos, e no $\S 1^{\circ}$ do mesmo artigo, delega ao poder público a proteção do patrimônio cultural brasileiro. Tudo isso demonstra a importância que a Carta reconhece à cultura africana como uma das 
diversas contribuições à formação do substrato cultural nacional.

Cabe, agora, a exposição e organização lógica da intricada legislação que garante o direito do qual aqui se trata, bem como dos trâmites admibnistrativos para que haja a identificação, o reconhecimento, a demarcação e a titulação da propriedade definitiva das terras ocupadas por remanescentes das comunidades dos quilombos reconhecidos pelo art. 68 do ADCT.

\section{REGRAMENTO JURÍDICO BRASILEIRO REFERENTE À REGULARIZAÇÃO DA PROPRIEDADE QUILOMBOLA: UMA SISTEMATIZAÇÃO}

A legislação brasileira parte do pressuposto de que a identidade quilombola depende de sua auto-identificação. De acordo com o Instituto Nacional de Reforma Agrária (INCRA), "as comunidades quilombolas são grupos étnicos - predominantemente constituídos pela população negra rural ou urbana -, que se autodefinem a partir das relações com a terra, o parentesco, o território, a ancestralidade, as tradições e práticas culturais próprias" (INCRA, 2015).

O auto-reconhecimento é, portanto, a etapa inicial para auferir o título da propriedade quilombola, conforme dispõe o art. $2^{\circ}, \S 1^{\circ}$ do Decreto n. 4.887/2003: "para os fins deste decreto, a caracterização dos remanescentes das comunidades dos quilombos será atestada mediante autodefinição da própria comunidade" (BRASIL, 2003). Dessa forma, ela deverá se constituir em uma pessoa jurídica e remeter o pedido à Fundação Cultural Palmares (FCP), órgão encarregado de analisar esse documento (onde consta, entre outros requisitos, a identificação histórica com a terra habitada pelos remanescentes) e emitir a certidão de acordo com a Portaria da Fundação Cultural Palmares n. 98/2007. Eis a letra do art. $3^{\circ}$, inc. I a V da referida portaria:

I - A comunidade que não possui associação legalmente constituída deverá apresentar ata de reunião convocada para específica finalidade de deliberação a respeito da autodefinição, aprovada pela maioria de seus moradores, acompanhada de lista de presença devidamente assinada;

II - A comunidade que possui associação legalmente constituída deverá apresentar ata da assembléia convocada para específica finalidade de deliberação a respeito da autodefinição, aprovada pela maioria absoluta de seus membros, acompanhada de lista de presença devidamente assinada; III - Remessa à FCP, caso a comunidade os possua, de dados, documentos ou informações, tais como fotos, reportagens, estudos realizados, entre outros, que atestem a história comum do grupo ou suas manifestações culturais; 
IV - Em qualquer caso, apresentação de relato sintético da trajetória comum do grupo (história da comunidade);

V - Solicitação ao Presidente da FCP de emissão da certidão de autodefinição (BRASIL, 2007).

Note-se o previsto nos inc. I e II do art. $3^{\circ}$, em relação às listas de presença que devem estar assinadas pelos presentes na reunião de debate sobre a autodefinição da comunidade.Dispõe o $\S 1^{\circ}$ do mesmo artigo:

Nos casos dos incisos I e II do caput deste artigo, havendo impossibilidade de assinatura de próprio punho, esta será feita a rogo ao lado da respectiva impressão digital (BRASIL, 2007).

Mesmo que a solicitação esteja fundamentada no art. $3^{\circ}$, I, acima transcrito, ressalta-se que o título de propriedade será em nome da pessoa jurídica, que deverá ser instituída para tal finalidade, conforme se verá.

As provas necessárias para a autodefinição da comunidade (acerca de antepassados, posse e permanência na terra, reminiscências arqueológicas, etc.) serão juntadas e avaliadas pela Fundação. A emissão da certificação será gratuita, de acordo com o art. $5^{\circ}, \S$ único, da Portaria n. 98 (BRASIL, 2007), e conterá o número do termo de registro no livro de Cadastro Geral de Remanescentes das Comunidades dos Quilombos, mantido pela Palmares, previsto no art. $1^{\circ}$ do mesmo dispositivo legal.Verificando as informações disponibilizadas pela Fundação Cultural Palmares, elaboramos a tabela e o gráfico que seguem:

\section{Comunidades quilombolas brasileiras certificadas até novembro de 2014 por região}

\begin{tabular}{|c|c|}
\hline UF & $\begin{array}{c}\text { Número de } \\
\text { comunidades } \\
\text { certificadas }\end{array}$ \\
\hline Norte & 301 \\
\hline Nordeste & 1.514 \\
\hline Centro-Oeste & 119 \\
\hline Sudeste & 340 \\
\hline Sul & 157 \\
\hline TOTAL & 2.431 \\
\hline
\end{tabular}

Comunidades certificadas por região

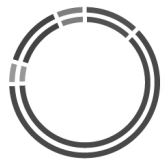

- NORTE - NORDESTE | CENTRO-OESTE | SUDESTE | SUL 
Observa-se a grande quantidade de comunidades certificadas na região nordeste do Brasil. Seguem-se as regiões sudeste, norte, sul e sudoeste, totalizando 2.431 quilombos. Na verdade, um número menos significativo do que o esperado, tendo em vista a longa trajetória escravocrata descrita acima.

Após emitir o certificado, a Fundação continua envolvida no procedimento, pois deverá conceder suporte para que a comunidade adquira a titulação definitiva da propriedade, emitida pelo INCRA. Além disso, garante assessoria jurídica às comunidades, seja para que defendam seus territórios contra qualquer tipo de violência, ou mesmo, para que desenvolvam projetos conectados a políticas públicas, conforme estabelece o Decreto n. 4.887 (BRASIL, 2003).

Por força do art. $3^{\circ}$ do mesmo decreto é do INCRA a competência no âmbito federal pelo procedimento de que tratamos neste texto, cabendo aos estados, Distrito Federal e municípios a competência concorrente (BRASIL, 2003). Daí a criação por esse instituto da Instrução Normativa n. 57, de 20 de outubro de 2009 (BRASIL, 2009), que regulamenta o procedimento para identificação, reconhecimento, delimitação, demarcação, desintrusão, titulação e registro das terras ocupadas por remanescentes das comunidades de quilombos. Há diversas normas estaduais que também regem o tema, sempre respeitando a legislação federal. Optamos, aqui, por sintetizar as etapas previstas nesta última, que se constitui a espinha dorsal da regularização fundiária quilombola.

A primeira etapa desse procedimento administrativo inicia-se pelo requerimento de qualquer interessado ou, mesmo, de ofício pelo INCRA, conforme disposto no art. $7^{\circ}, \S 4^{\circ}$ da instrução normativa (BRASIL, 2009) e do art. $3^{\circ}, \S 3^{\circ}$ do Decreto $n$. 4.887 (BRASIL, 2003). Assim, a comunidade encaminha à Superintendência Regional do INCRA do seu Estado o pedido para a regularização de território junto com a certidão de registro no Cadastro Geral de Remanescentes de Comunidades de Quilombos, conforme indicado anteriormente.Segundo informação disponibilizada pelo Instituto, até julho de 2014 existiam 1.290 procedimentos abertos na abrangência das Superintendências Regionais, excetuando-se Roraima, Marabá/PA e Acre (INCRA, 2014).

A comunidade poderá acompanhar o procedimento por meio de seus associados ou por representante por ela constituído, uma vez que será a principal beneficiada deste procedimento (art. $6^{\circ}$ do Decreto n. 4.887) (BRASIL, 2003). Entidades como a Secretaria Especial de Políticas de Promoção da Igualdade Racial e o Ministério da Cultura (art. $4^{\circ}$ e $5^{\circ}$ do Decreto n. 4.887) (BRASIL, 2003) devem assistir, acompanhar e fiscalizar todas as etapas, garantindo a eficácia dos direitos da comunidade. Cabe a essas entidades, bem como à comunidade interessada, acompanhar $\mathrm{e}$ 
fornecer informações necessárias, dentro de suas possibilidades, para a elaboração do Relatório Técnico de Identificação e Delimitação (RTID). Este é um documento produzido por uma equipe multidisciplinar do INCRA, objetivando a identificação e a delimitação do território quilombola reivindicado.

Nessa segunda etapa, o Instituto faz um estudo da área onde a comunidade se encontra, destinado à elaboração do RTID, contendo informações cartográficas, fundiárias, agronômicas, ecológicas, socioeconômicas, históricas e antropológicas daquele contexto. Dispõe o art. $9^{\circ}$ da Instrução Normativa n. 57:

A identificação dos limites das terras das comunidades remanescentes de quilombos a que se refere o art. $4^{\circ}$, a ser feita a partir de indicações da própria comunidade, bem como a partir de estudos técnicos e científicos, inclusive relatórios antropológicos, consistirá na caracterização espacial, econômica, ambiental e sociocultural da terra ocupada pela comunidade, mediante Relatório Técnico de Identificação e Delimitação - RTID, com elaboração a cargo da Superintendência Regional do INCRA, que o remeterá, após concluído, ao Comitê de Decisão Regional, para decisão e encaminhamentos subsequentes (BRASIL, 2009).

Esse estudo, bem como a definição e demarcação do território, será precedido de reuniões com a comunidade e um grupo técnico interdisciplinar, a fim de dar transparência às decisões acerca dos procedimentos adotados. O RTID será elaborado, preferencialmente, por especialista que mantenha vínculo funcional com o INCRA, conforme o art. 10, VI, $\S 2^{\circ}$ da instrução normativa (BRASIL, 2009). Após concluir os trabalhos, o Instituto publica edital no Diário Oficial da União (D.O.U) e do estado federativo contendo informações sobre a área onde foi feito o relatório, obedecendo ao disposto no art. 11 da instrução normativa (BRASIL, 2009) e a letra do art. $7^{\circ}$ do Decreto n. 4.887 , que assim está redigido:

O INCRA, após concluir os trabalhos de campo de identificação, delimitação e levantamento ocupacional e cartorial, publicará edital por duas vezes consecutivas no Diário Oficial da União e no Diário Oficial da unidade federada onde se localiza a área sob estudo, contendo as seguintes informações:

I - denominação do imóvel ocupado pelos remanescentes das comunidades dos quilombos;

II - circunscrição judiciária ou administrativa em que está situado o imóvel; III - limites, confrontações e dimensão constantes do memorial descritivo das terras a serem tituladas; e 
IV - títulos, registros e matrículas eventualmente incidentes sobre as terras consideradas suscetíveis de reconhecimento e demarcação (BRASIL, 2003).

Contam-se em número de 169 os editais de relatórios publicados até julho de 2014, segundo os dados mais atualizados disponibilizados pelo INCRA (2014). De acordo com o art. 12 da Instrução Normativa n. 57 (BRASIL, 2009) e $8^{\circ}$ do decreto (BRASIL, 2003), o Instituto deverá, ainda, consultar uma série de órgãos e entidades acerca do relatório, tais como a Fundação Nacional do Índio e o Instituto do Patrimônio Histórico e Artístico Nacional. O art. 13 da instrução normativa (BRASIL, 2009) e $9^{\circ}$ do decreto (BRASIL, 2003) estabelecem que, após a publicação do RTID, abre-se o prazo de 90 dias para contestações de interessados particulares ou outros órgãos governamentais. Seu art.14 determina:

As contestações dos interessados indicados no art. 12 serão analisadas e julgadas pelo Comitê de Decisão Regional do INCRA, após ouvidos os setores técnicos e a Procuradoria Regional em prazo comum de até 180 (cento e oitenta) dias, a contar do protocolo da contestação (BRASIL, 2009).

Procedentes as contestações, retifica-se e republica-se o edital. Improcedentes, o RTID é aprovado em definitivo. Tendo por base esse relatório, o INCRA publica no D.O.U e no Diário Oficial do Estado portaria que reconhece e declara os limites do território quilombola- art. 17 da instrução normativa (BRASIL, 2009). Em julho de 2014, somavam-se 89 portarias publicadas (INCRA, 2014).

A fase seguinte do processo administrativo corresponde à regularização fundiária, com desintrusão de ocupantes não quilombolas mediante desapropriação e/ou pagamento de indenização e demarcação do território. No caso deste se localizar em terras públicas, a etapa torna-se desnecessária, pois, sendo terras da União, a propriedade será titulada pelo INCRA ou pela Secretaria de Patrimônio da União (SPU); em terras estaduais ou municipais, a titulação será realizada pelo respectivo ente federativo- art. 10 e 12 do Decreto n. 4.887 (BRASIL, 2003) e art. 18 e 20 da Instrução Normativa n. 57 (BRASIL, 2009).

Pode ocorrer, entretanto, que a área quilombola localize-se em domínio particular. Nesse caso, o Presidente da República deverá editar um decreto de desapropriação por interesse social. Dados do INCRA dão notícia de 63 decretos publicados até julho de 2014 (INCRA, 2014). As propriedades particulares de pessoas não quilombolas serão avaliadas pelo INCRA, sendo desapropriadas e indenizadas, pelo preço de mercado e em dinheiro - art. 13 do decreto (BRASIL, 2003) e art. 21 
da instrução normativa (BRASIL, 2009).

Por fim, a titulação, a última etapa do procedimento. A normatização jurídica impõe que o título seja coletivo, pró-indiviso e em nome da pessoa jurídica que representa a comunidade. Além disso, necessitam ser inseridas cláusulas de inalienabilidade, imprescritibilidade e impenhorabilidade, registrando-o na comarca de localização do terreno, de acordo com os art. 24 e 25 da Instrução Normativa n. 57 (BRASIL, 2009) e art. 17 do decreto (BRASIL, 2003). Tem-se, hoje, 154 títulos definitivos emitidos (INCRA, 2014).

A legislação que estabelece todas essas etapas é, por vezes, intricada e sobreposta. Com a finalidade de melhor visualizar os passos do procedimento abordado, elaboramos o fluxograma que segue.

\section{Fluxograma do procedimento estabelecido pela legislação federal}

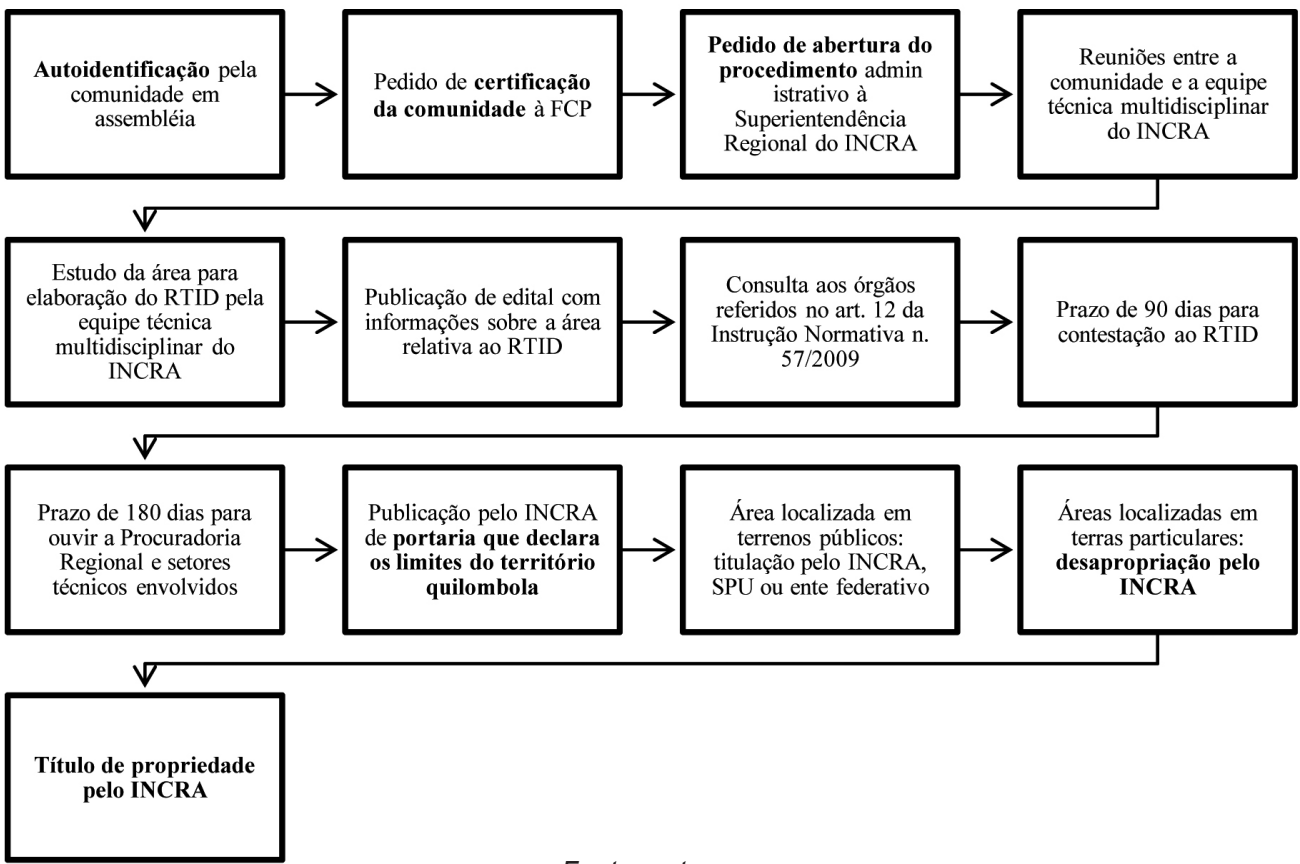

Fonte: autores

Visualiza-se, desse modo, a longa trajetória pela qual devem percorrer os remanescentes de quilombos a fim de que lhes seja efetivado o título de propriedade. Poderíamos nos referir aqui ao percurso trilhado por negros cativos, coisificados por um sistema jurídico escravocrata. Ou por seus herdeiros contemporâneos, cuja 
diferenciação em termos de alfabetização, escolaridade e remuneração faz parte das inúmeras estatísticas que demonstram o abismo étnico e social brasileiro. Optamos por observar, neste momento, o extenso e minucioso aparato legal que cerca o procedimento aqui descrito.

A Constituição Federal, na qual se deu o reconhecimento do direito abordado, data de 1988. A ratificação da Convenção 169 da OIT pelo Brasil ocorreu em 2002. O Decreto n. 4.887 está em vigor desde 2003. Apesar de toda nossa ascendência negra, hoje contamos com apenas 2.431 comunidades quilombolas certificadas e um baixo número de pedidos de abertura de procedimento: 1.290 ao todo. Ao fim, quase 30 anos após a promulgação da Magna Carta, temos o resultado atual dessa estrutura configurado nos 154 títulos dominiais definitivos de territórios quilombolas.

Diversas podem ser as razões para isso: o desconhecimento de direitos básicos pelas comunidades; o analfabetismo - reconhecido até mesmo pela Portaria FCP n. 98/2007, art. $3^{\circ}, \S 1^{\circ}$ (BRASIL, 2007) -, que dificulta inclusive a constituição de uma pessoa jurídica que represente o grupo; a teia intricada de regras jurídicas que acabamos de verificar. E, no entanto, o texto constitucional deve, necessariamente, ser efetivado. Seus princípios, como o da igualdade e da função social da propriedade, seus direitos, tais como os culturais, não estão ali apenas para representar um consenso político. A propriedade quilombola é reconhecida como direito fundamental, ainda que fora do catálogo dos art. $5^{\circ}$ ao 17 (BRASIL, 1988).

Mais preocupante ainda, é a tentativa de impor um regresso nesses direitos, configurada na tramitação da Ação Direta de Inconstitucionalidade n.3239 (STF, 2004), que questiona a procedimentalização pelo Decreto 4.887 (BRASIL, 2003). Compreendido o direito de que tratamos como fundamental, incide sobre ele uma proibição de retrocesso. Dessa forma:

[...] reitera-se a nossa posição em prol da possibilidade de uma aplicaçãoda noção de proibição de retrocesso, desde que tomada em sentido amplo, nosentido de uma proteção dos direitos contra medidas de cunho restritivo, atodos os direitos fundamentais. Assim, verifica-se que a designação proibição de retrocesso social [...] opera precisamente na esfera dos direitos sociais,especialmente no que diz com a proteção "negativa" (vedação da supressão ou diminuição) (SARLET, 2009, p. 123).

Nota-se que o tema ainda gera debates e controvérsia. Entendemos, entretanto, que é tarefa de todos nós - juristas ou não - nos empenharmos para garantir a concretude dessas garantias, pois "diante de tais números e de tanta 
informação disponível sobre o assunto ninguém mais goza do benefício da ignorância quanto ao tema. Ignorância é não saber. Indiferença é saber, mas não se importar" (SOUZA, 2006, p. 81).

\section{CONCLUSÃO}

Fizemos, inicialmente, um breve relato sobre escravidão e resistência negra no Brasil. Os cativos trazidos a força para estas terras tiveram sua relação direta com a formação histórica, cultural e com desenvolvimento nacional, reconhecida pela Constituição Federal de 1988. Entretanto, mesmo anos após a abolição, o abismo social que separa negros de brancos reflete-se nas estatísticas contemporâneas: elas retratam uma realidade que passa ao largo de garantias constitucionais e legislações infraconstitucionais.

Podemos verificar, igualmente, a vasta legislação que garante o direito de propriedade quilombola, descrevendo o procedimento que deve ser realizado, assim como as tarefas das respectivas instituições envolvidas. Confrontando as normas jurídicas aqui indicadas, podemos concluir pela sua extrema burocratização e pela demora na prestação de um direito há muito reconhecido. Não podemos arcar com o custo social suscitado pelo desrespeito aos direitos fundamentais, tal como o que aqui se trata. Tanto o Estado quanto a sociedade civil têm o dever de efetivar o constitucionalmente previsto, sem permitir retrocessos nessas garantias. E permitir também a visibilidade dos problemas dessas comunidades negras, marginalizadas e pobres que estão entregues, muitas vezes, à própria sorte.

\section{REFERÊNCIAS}

ALVES, Castro. Navio Negreiro. Disponível em http://www.culturabrasil.org/navionegreiro. htm. Acessado em 29 de janeiro de 2015.

ANJOS, Rafael Sanzio Araújo; CIPRIANO, André. Quilombola: Tradições e Cultura da Resistência. São Paulo:Aori Comunicações, 2006.

BRASIL. Lei n. 601 de 18 de setembro de 1850. Disponível em: http://www.planalto.gov. br/ccivil_03/Leis/L0601-1850.htm. Acessado em 10 de fevereiro de 2015. 
BRASIL. Constituição da República Federativa do Brasil de 1988. Disponível em: http:// www.planalto.gov.br/ccivil_03/constituicao/constituicaocompilado.htm. Acessado em 05 de janeiro de 2015.

BRASIL. Código Civil, Lei n. 10.406, de 10 de janeiro de 2002. Disponível em: http:// www.planalto.gov.br/ccivil_03/leis/2002/110406.htm. Acessado em 05 de janeiro de 2015.

BRASIL. Decreto n. 4.887, de 20 de novembro de 2003. Disponível em: https: //legislação. planalto.gov.br/legislação. Acessado em 05 de janeiro de 2015.

BRASIL. Portaria n. 98, de 26 de novembro de 2007. Disponível em: http://www.palmares.gov.br/legislação. Acessado em 15 de fevereiro de 2015.

BRASIL. Instrução Normativa n. 57, do INCRA, de 20 de outubro de 2009. Disponível em: http://www.incra.gov.br/portal. Acessado em 05 de janeiro de 2015.

BRILHANTE, Tércio Aragão. Escravidão Negra no Brasil: Questões de Política, Direito, Literatura e Filosofia. Anais do XVIII Congresso Nacional do CONPEDI, realizado em São Paulo nos dias 04, 05, 06 e 07 de novembro de 2009. In: http://www.publicadireito. com.br/conpedi/manaus/arquivos/Anais/sao_paulo/2880.pdf. Acessado em 20 de dezembro de 2014 .

CIRNE, Mariana Barbosa. A (Pré) Compreensão de uma Propriedade que Trabalha contra sua Função Social. In: Congresso Nacional de Pesquisa e Pós-Graduação em Direito, 2010, Fortaleza. Anais do XIX Encontro Nacional do CONPEDI, Florianópolis, Fundação Boiteux, 2010. Disponível em: http://www.conpedi.org.br/manaus/arquivos/anais/fortaleza/Integra.pdf. Acessado em 02 de fevereiro de 2015.

COTTROL, Robert. Brow and the Contemporary Brazilian Struggle Against Racial Inequality: some preliminary comparative thoughts. Universityof Pittsburgh Law Review, n. 66,p. 113-129, 2004.

DE LEÓN, Zênia, Memórias da Escravidão. Pelotas: Editora do Autor, 1991.

FREITAS, Décio. O Escravismo Brasileiro. 3 ed. Porto Alegre: Mercado Aberto, 1991.

FUNDAÇÃO CULTURAL PALMARES.Comunidades quilombolas brasileiras certificadas até novembro de 2014 por região. Disponível em: http://www.palmares.gov.br/ wp-content/uploads/crqs/quadro-geral-por-regiao-ate-27-11-2014.pdf. Acessado em 20 de fevereiro de 2015 . 
GOMES, Flávio dos Santos. Sonhando com a Terra, Construindo Cidadania. In: PINSKI, Jaime; PINSKI, Carla Bassanezi (orgs). História da Cidadania. 4. ed. São Paulo: Contexto, 2008.p. 447-467.

GUTIERREZ, Ester Judite Bendjouya. Sítio Charqueador Pelotense. In: BOEIRA, Nelson; GOLIN, Tau (coords.). Império. Passo Fundo: Méritos, 2006. p. 231-256.

HENNING, Ana Clara Correa et al. Remanescentes de Quilombos Pelotenses: paradigma emergente, dignidade humana e propriedade. In: Revista África e Africanidades, ano 3, n. 9, maio, 2010. Disponível em:http://www.africaeafricanidades.com.br/documentos/Remanescentes_quilombos_pelotenses.pdf. Acessado em 08 de janeiro de 2015.

INCRA. Instituto Nacional de Reforma Agrária. Quadro atual da política de regularização dos territórios quilombolas em julho de 2014. In: http://www.incra.gov.br/sites/default/ files/quadro_atual_politica_regularizacao_territorios_quilombolas.pdf. Acessado em 12 de fevereiro de 2015.

INCRA. Instituto Nacional de Reforma Agrária. Quilombolas. Disponível em: http://www. incra.gov.br/quilombolas. Acessado em 12 de fevereiro de 2015.

IPEA. Instituto de Pesquisa Econômica Aplicada. Retrato das desigualdades de gênero e raça - 2012. Disponível em: http://www.ipea.gov.br/retrato/indicadores.html. Acessado em 16 de janeiro de 2015.

LAGO, Luiz Aranha Corrêa do. Da escravidão ao trabalho livre - Brasil, 1550-1900. São Paulo: Companhia das Letras, 2014.

MALMANN, Germene. As Comunidades Remanescentes de Quilombo e o Art. 68 do ADCT: propriedade da terra, reconhecimento e cidadania. Revista de Direito Brasileira, ano 1, v. 1, p. 265-289,jul/dez, 2011.

MIRANDA, Jorge. Teoria do Estado e da Constituição. Rio de Janeiro: Forense, 2002.

MÜLLER, Cíntia Beatriz. Direitos Étnicos e Territorialização: dimensões da territorialidade em uma comunidade negra gaúcha. Porto Alegre: Editora da UFRGS, 2011.

NASCimento, Tupinambá Miguel Castro do. Posse e Propriedade. 3 ed. Porto Alegre: Livraria do Advogado, 2003.

NOGUEIRA, Ana Carolina Del Picchia de Araújo. Função socioambiental do direito de propriedade. Em Tempo, Marília, v. 12, p. 61-82, 2013. 
OIT. Organização Internacional do Trabalho. Convenção n. 169, ratificada em 2002. Disponível em: http://www.oit.org.br/node/513. Acessado em 01 de fevereiro de 2015.

PENTEADO, Leandro Camargo. Direito das Coisas. São Paulo: Revista dos Tribunais, 2008 .

PERLINGIERI, Pietro. O Direito Civil na Legalidade Constitucional. Tradução de Maria Cristina de Cicco. Rio de Janeiro: Renovar, 2008.

RUBERT, Rosane. Comunidades negras no RS: o redesenho do mapa estadual. In: SILVA, Gilberto Ferreira da; SANTOS, José Antônio dos; CARNEIRO, Luiz Carlos da Cunha (orgs). RS NEGRO: cartografias sobre a produção do conhecimento. Porto Alegre: PUCRS, 2008.p. 165-181.

SARLET, Ingo Wolfgang. A Eficácia dos Direitos Fundamentais: uma teoria geral dos direitos fundamentais na perspectiva constitucional.10 ed. Porto Alegre: Livraria do Advogado, 2010.

SARLET, Ingo Wolfgang. Notas sobre a assim designada proibição de retrocesso social no constitucionalismo latino-americano.Revista do TST, Brasília, vol. 75, n. 3, p. 116-149, jul/ set, 2009.

SOUZA, Marina de Mello. África e Brasil Africano. São Paulo: Ática, 2006.

STF. Supremo Tribunal Federal. Ação Direta de Inconstitucionalidade n.3239/2004. Disponível em: http://www.stf.jus.br/portal/peticaoInicial/verPeticaoInicial. asp?base $=\mathrm{ADIN} \& \mathrm{~s} 1=3239 \% 20 \&$ processo=3239. Acessado em 20 de fevereiro de 2015 . 